\title{
MAPEAMENTO DA PRODUÇÃO DO CONHECIMENTO SOBRE A MODALIDADE DO BASQUETEBOL NOS PERIÓDICOS BRASILEIROS ${ }^{1}$
}

\author{
Luiz Fernando Gonçalves \\ Universidade Federal do Paraná, Curitiba, Paraná, Brasil \\ Jeferson Roberto Rojo \\ Universidade Federal do Paraná, Curitiba, Paraná, Brasil \\ Fernando Renato Cavichiolli \\ Universidade Federal do Paraná, Curitiba, Paraná, Brasil \\ Marcelo Moraes e Silva \\ Universidade Federal do Paraná, Curitiba, Paraná, Brasil
}

\begin{abstract}
Resumo
O presente estudo tem como objetivo mapear a produção do conhecimento sobre a modalidade basquetebol publicada em periódicos brasileiros, no período entre os anos de 2010 e 2015. O levantamento apontou que a produção sobre o basquetebol somou 66 artigos, distribuídos em 18 periódicos científicos, sendo o maior número sobre treinamento esportivo. No que tange à classificação por estratos do Qualis, é predominante os que estão classificados no estrato B1. Também foi observada uma tendência na produção na forma de uma rede de colaboração de autores. A título de conclusão, o estudo aponta que a produção sobre o basquetebol, apesar de pequena quantitativamente e com predominância na temática de treinamento, apresenta-se diversificada epistemologicamente.
\end{abstract}

Palavras-chave: Basquetebol. Produção do Conhecimento. Periódicos.

\section{Introdução}

As práticas relacionadas ao basquetebol ocupam um cenário amplo de possibilidades que perpassam a educação física escolar, o desenvolvimento de valores preconizados em projetos sociais, as atividades de lazer, o exercício físico voltado à manutenção da saúde e o rendimento em competições. Dessa forma, compreender o basquetebol pressupõe contemplá-lo em sua complexidade de práticas e significados no interior da sociedade em que se insere. Com isso, surge a proposta de mapeamento acerca de sua produção científica, buscando verificar se a produção do conhecimento sobre a modalidade tem acompanhado essa diversidade de apropriação do basquetebol.

\footnotetext{
${ }^{1} \mathrm{O}$ presente artigo contou com financiamento da CAPES.
} 
Nesse sentido, o presente estudo busca responder à seguinte problemática de pesquisa: qual o atual quadro da produção do conhecimento sobre a modalidade basquetebol, publicada em português, entre os anos de 2010 e 2015 ?

A pesquisa tem como objetivo mapear a produção científica escrita em língua portuguesa publicada em periódicos brasileiros. Propõe-se apresentar algumas particularidades da literatura científica, identificando as temáticas mais atendidas, os locais de publicação, os estratos destes periódicos no sistema Qualis, bem como os autores e instituições com maior número de artigos publicados e suas redes de colaboração. A partir desta descrição, visa-se compreender a lógica que movimenta a produção científica sobre o basquetebol.

\section{Metodologia}

O presente estudo caracteriza-se como exploratório e descritivo, no qual realizou-se um mapeamento da produção científica sobre a modalidade do basquetebol disponível em periódicos brasileiros. Elegeram-se para compor o escopo os artigos indexados nas seguintes bases de dados: Lilacs e Medline, acessados por meio da interface da Biblioteca Virtual da Saúde (BVS-BIREME), Scielo e Portal de Periódicos da CAPES. Estas foram escolhidas por serem abrangentes, em termos de indexação de um maior número de periódicos, visto que nestas bases se encontram revistas de diferentes estratos e de distintas áreas do conhecimento.

As buscas foram feitas em dezembro de 2015 com a utilização de três descritores: "Basquete", "Basquetebol" e "Basketball". Selecionaram-se para compor o escopo da pesquisa apenas artigos em periódicos brasileiros disponíveis on-line, publicados no período entre os anos de 2010 e 2015. Os anos correspondem ao período de avaliação da Coordenação de Aperfeiçoamento de Pessoal de Nível Superior (CAPES), triênio (2010-2011-2012) e do quadriênio em andamento (2013-2014-2015-2016).

Foram excluídos artigos publicados em outras línguas, bem como resenhas e textos que, embora citassem o basquetebol, não tinham como foco alguma temática diretamente relacionada à modalidade. Os artigos encontrados em mais de uma base de dados foram considerados uma única vez. Após as buscas nos três bancos de dados e a utilização dos critérios de exclusão, foram selecionados para o mapeamento 66 artigos.

Para realizar a categorização dos artigos, utilizaram-se os seguintes procedimentos: 1) leitura dos os resumos e, quando necessário, dos trabalhos completos; 2) relação dos principais assuntos discutidos pelos artigos. Após essa etapa, o próximo passo foi o de distribuir os artigos nos eixos temáticos levantados por Souza, Moraes e Silva e Moreira (2016). Nesse sentido, os artigos relativos ao basquetebol foram distribuídos dentro dos seguintes eixos temáticos:

Treinamento: espaços e equipamentos relacionados à performance, aspectos motores, fisiológicos, técnicos, táticos e biomecânicos relacionados ao rendimento.

Iniciação Esportiva e Categorias de Base: metodologia de ensino, aprendizagem motora, treinamento de jovens atletas e seleção de talentos esportivos.

Saúde: promoção, manutenção e reabilitação da saúde, lesões e patologias.

Aspectos Educacionais: aspectos pedagógicos e educacionais do esporte na escola e em processos de escolarização.

Administração, Financiamento e Políticas Públicas: legislação, gestão, financiamento e administração esportiva.

Aspectos Sociais, Culturais e Históricos: aspectos sociológicos, antropológicos e históricos relacionados com o esporte (discussões sobre temáticas tais como gênero, mídia, violência, valores etc.). 
Aspectos Psicológicos: motivação, emoções, autoimagem, transtornos psicológicos/alimentares, personalidade, concentração, comportamento e humor.

Aspectos Nutricionais: perfil dietético e suplementação alimentar.

Para os fins do mapeamento, foram catalogadas as seguintes informações contidas nos artigos: ano de publicação, área de conhecimento, revista, estratificação no Qualis ${ }^{2}$, temática central, autores e instituições. As informações dos seis pesquisadores com maior número de publicação foram retiradas do Currículo Lattes de cada um.

Para a exposição dos resultados da pesquisa, inicialmente apresentam-se os números gerais indicando a quantidade de publicações sobre o basquetebol referente a cada um dos enfoques temáticos. Na sequência, detalharam-se os assuntos abordados em cada um dos eixos e, posteriormente, apresentam-se os autores e instituições com maior produtividade.

\section{Resultados e discussão}

Para começar o mapeamento, torna-se necessário visualizar a distribuição dos artigos ano a ano, conforme mostra o Gráfico 1:

Gráfico 1- Distribuição da produção do conhecimento por ano analisado - Sistematizado pelos autores

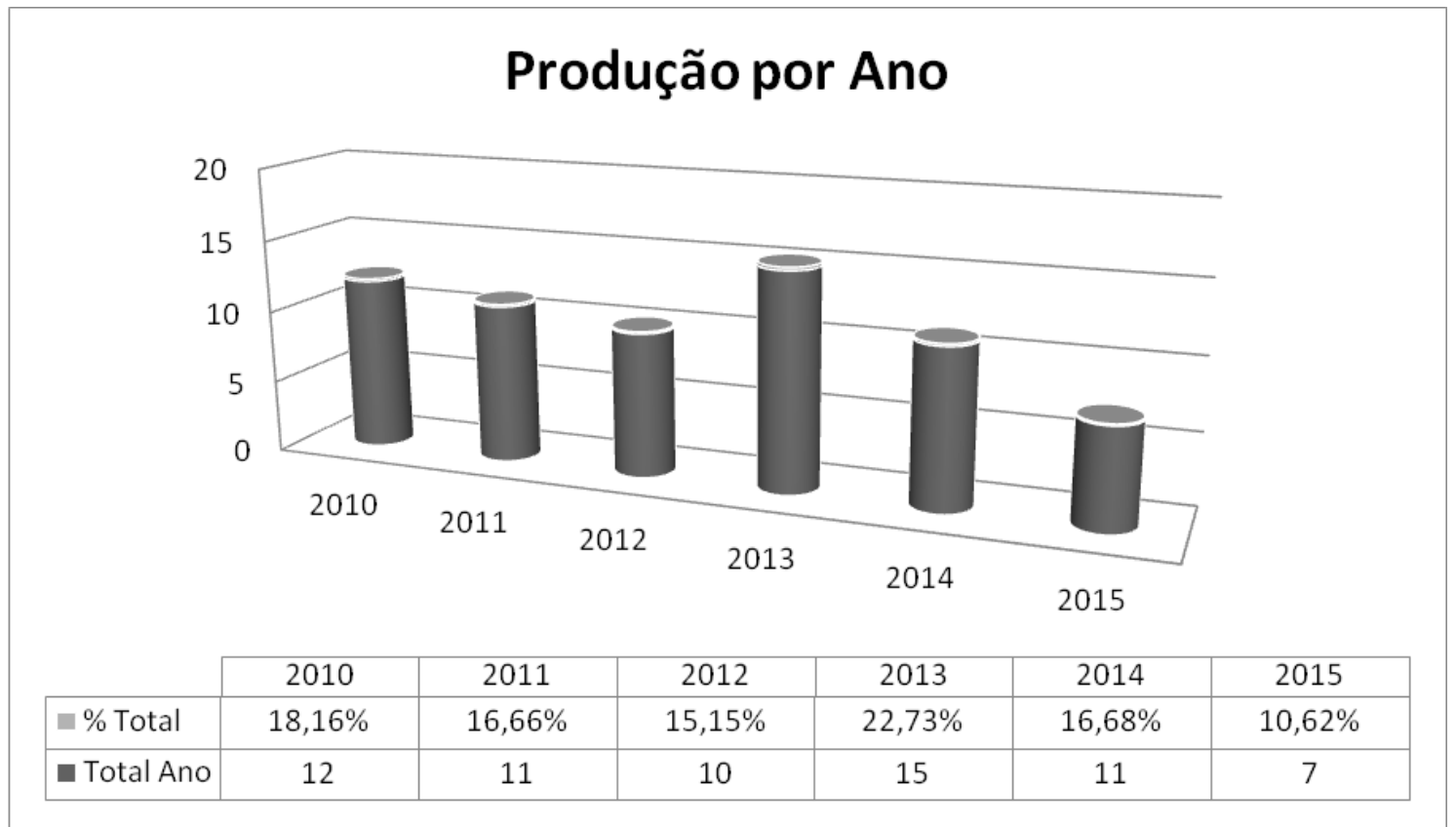

Fonte: Elaborado pelos autores, 2016.

O Gráfico 1 representa a distribuição por ano dos 66 artigos selecionados. O ano de 2013 aparece com um número maior de publicações. O menor índice é registrado no ano de 2015, com sete manuscritos. Ao analisar a disposição da produção, observa-se uma repartição relativamente proporcional para cada ano, com uma pequena alta em 2013, primeiro ano do atual quadriênio avaliativo da CAPES. Em relação à menor produção registrada em 2015, a

\footnotetext{
${ }^{2}$ Os manuscritos foram distribuídos pela classificação do WebQualis válido do ano de 2014, referente a área 21 da CAPES (Educação Física, Fisioterapia, Fonoaudiologia e Terapia Ocupacional). Disponível em: $<$ https://sucupira.capes.gov.br/sucupira/public/consultas/coleta/veiculo PublicacaoQualis/listaConsultaGeralPeriodicos.jsf >. Acesso em: 1 jul. 2015.
} 
explicação pode ser pelo fato de vários periódicos ainda não terem colocados seus artigos nessas bases indexadoras ${ }^{3}$.

Já em relação à distribuição por estrato no Qualis, não existe um equilíbrio, conforme pode ser visto no gráfico abaixo:

Gráfico 2 - Distribuição da produção por estrato do Qualis - Sistematizado pelos autores.

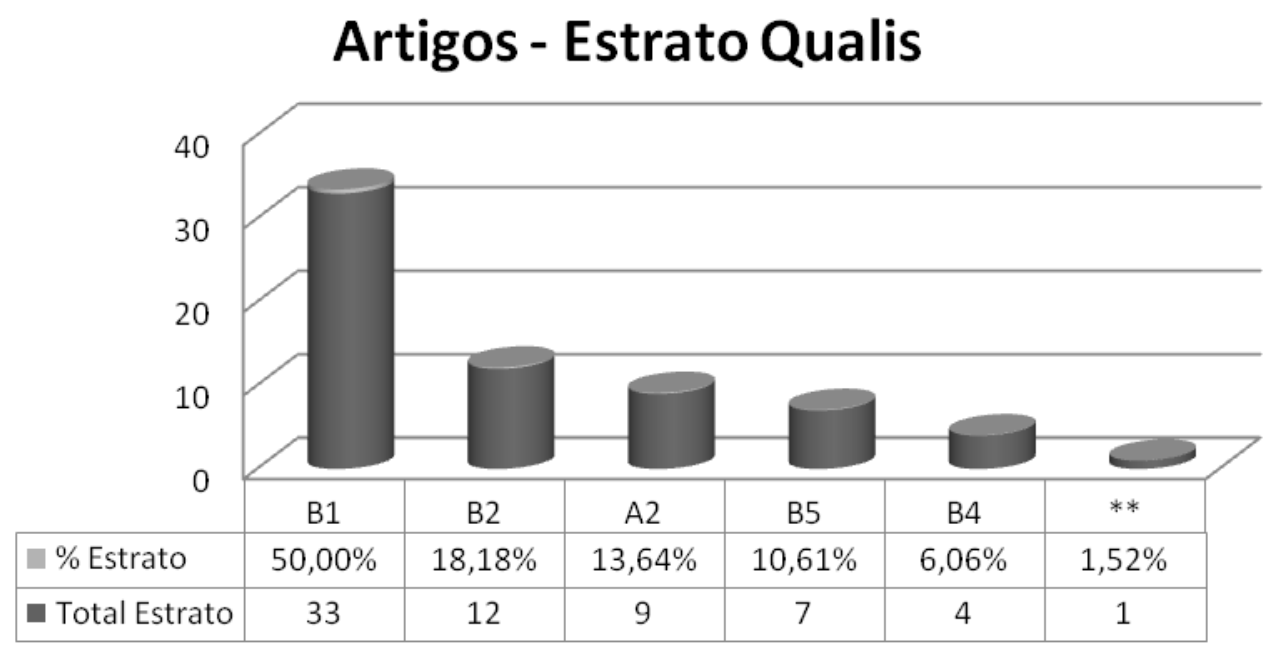

** Não classificado no Qualis da Educação Física.

Fonte: Elaborado pelos autores, 2016.

Os artigos publicados em periódicos com estrato B1 são em maior número, seguido pelas publicações B2. Nos estratos mais elevados do sistema de avaliação da CAPES, encontram-se nove manuscritos, todos na classificação A2. O A1 não contém nenhum manuscrito, visto que, conforme lembra Tani (2014), não existem periódicos brasileiros que se encontram nessa classificação dentro do Qualis da área de Educação Física.

Os estratos B4 e B5 somam 11 artigos (16,67\%). O B3 não apresentou nenhuma publicação sobre a modalidade durante o período do recorte da pesquisa. Dentre os artigos selecionados para o estudo, apenas um $(1,5 \%)$ não estava enquadrado no Qualis referente à Educação Física. Esse manuscrito revela que o basquetebol também é motivador de pesquisas em outras áreas do conhecimento. O estudo é uma pesquisa da área da saúde, que analisa as principais lesões musculoesqueléticas sofridas por jovens atletas de basquetebol.

A abrangência do esporte, mais precisamente do basquetebol, em diferentes áreas do conhecimento, é observada pela diversidade de periódicos nos quais se encontram as publicações sobre a modalidade. Ao contabilizar os locais de divulgação dos artigos analisados, encontraram-se 18 revistas.

\footnotetext{
${ }^{3} \mathrm{O}$ fato de determinados artigos ainda não estarem disponibilizados em bases indexadoras não indica que determinado periódico esteja necessariamente atrasado. O que ocorre é que algumas revistas, apesar de estarem com suas edições em dia, ainda não se encontram disponíveis nas bases indexadoras pesquisadas. Nesse sentido, não é possível identificar os periódicos em atraso, pois a pesquisa foi feita tendo como parâmetros os descritores e não os títulos das revistas.
} 
Tabela 1 - Revistas que publicaram artigos sobre basquetebol - Sistematizado pelos autores

\begin{tabular}{|c|c|c|c|}
\hline Periódicos & Qualis & $\begin{array}{l}\text { Número de arti- } \\
\text { gos }\end{array}$ & $\%$ \\
\hline Revista Brasileira de Educação Física e Esporte (RBEFE) & B1 & 9 & $13,64 \%$ \\
\hline Revista Brasileira de Medicina do Esporte (RBME) & A2 & 9 & $13,64 \%$ \\
\hline Revista Brasileira de Ciências do Esporte (RBCE) & B1 & 6 & $9,09 \%$ \\
\hline Motriz & B1 & 5 & $7,58 \%$ \\
\hline $\begin{array}{l}\text { Revista Brasileira de Cineantropometria e Desempenho Humano } \\
\qquad(\mathrm{RBCDH})\end{array}$ & B1 & 5 & $7,58 \%$ \\
\hline Revista de Educação Física/UEM & B1 & 5 & $7,58 \%$ \\
\hline Conscientia e Saúde & B2 & 4 & $6,06 \%$ \\
\hline Revista Brasileira de Ciência e Movimento (RBCM) & B2 & 4 & $6,06 \%$ \\
\hline Revista Brasileira de Futsal e Futebol (RBFF) & B5 & 4 & $6,06 \%$ \\
\hline Revista Brasileira de Prescrição e Fisiologia do Exercício (RBPFE) & B4 & 4 & $6,06 \%$ \\
\hline Revista Brasileira de Ortopedia (RBO) & B2 & 3 & $4,55 \%$ \\
\hline Podium: Sport, Leisure and Tourism Review & B5 & 2 & $3,03 \%$ \\
\hline Fisioterapia e Pesquisa & B1 & 1 & $1,52 \%$ \\
\hline Fisioterapia em Movimento & B1 & 1 & $1,52 \%$ \\
\hline Revista Brasileira de Clínica Médica & B2 & 1 & $1,52 \%$ \\
\hline Revista de Terapia Ocupacional da Universidade de São Paulo & B1 & 1 & $1,52 \%$ \\
\hline Revista Saude.Com & $* *$ & 1 & $1,52 \%$ \\
\hline Salusvita & B5 & 1 & $1,52 \%$ \\
\hline Total Geral & & 66 & $\begin{array}{c}100,00 \\
\%\end{array}$ \\
\hline
\end{tabular}

Fonte: Elaborado pelos autores, 2016.

A Tabela 1 apresenta os periódicos que tiveram publicações durante a temporalidade da pesquisa. Os que mais vincularam em suas páginas estudos sobre o basquetebol foram a $R B M E$ e a $R B E F E$, que somaram nove publicações cada uma. Com a menor incidência de publicação, aparecem seis periódicos com uma única publicação. Como pode ser observado, existe uma diversidade epistemológica dos locais nos quais os artigos têm sido divulgados, como pode ser observado na Tabela 2 :

Tabela 2 - Escopo dos periódicos - Sistematizado pelos autores ${ }^{4}$

\begin{tabular}{cc}
\hline Periódicos & Escopo \\
\hline ConScientiae Saúde & $\begin{array}{c}\text { Caráter multidisciplinar relacionado à área } \\
\text { Ciências da Saúde e suas interfaces }\end{array}$ \\
\hline Fisioterapia e Pesquisa & Não há informações no site \\
\hline Fisioterapia em Movimento & $\begin{array}{c}\text { Pesquisas na área da Fisioterapia e na grande } \\
\text { área da saúde }\end{array}$ \\
\hline Motriz & $\begin{array}{c}\text { Pesquisas originais em Ciências do Movimento } \\
\text { Humano e áreas relacionadas com o desporto e } \\
\text { o exercício físico }\end{array}$ \\
\hline Podium: Sport, Leisure and Tourism Review & $\begin{array}{c}\text { Gestão de organizações esportivas, de lazer e } \\
\text { de turismo, abrangendo disciplinas da Adminis- } \\
\text { tração de Empresas, bem como interconexões } \\
\text { com o Direito, a Economia, a História, a Socio- } \\
\text { logia, a Antropologia e a Educação Física }\end{array}$ \\
\hline Revista Brasileira de Ciência e Movimento & $\begin{array}{c}\text { Áreas da atividade física, do exercício e do } \\
\text { esporte }\end{array}$ \\
\hline
\end{tabular}

\footnotetext{
${ }^{4}$ As informações contidas na Tabela 2 foram encontradas nos portais eletrônicos de cada periódico.
} 


\begin{tabular}{|c|c|}
\hline Revista Brasileira de Ciências do Esporte & Educação Física/Ciências do Esporte \\
\hline $\begin{array}{l}\text { Revista Brasileira de Cineantropometria e Desempe- } \\
\text { nho Humano }\end{array}$ & $\begin{array}{l}\text { Ciência do movimento humano, com ênfase na } \\
\text { cineantropometria nas suas vertentes morfoló- } \\
\text { gica e funcional, bem como os fatores condici- } \\
\text { onantes do desempenho físico }\end{array}$ \\
\hline Revista Brasileira de Clínica Médica & $\begin{array}{l}\text { Conhecimento médico e atualização dos profis- } \\
\text { sionais relacionados à saúde }\end{array}$ \\
\hline Revista Brasileira de Educação Física e Esporte & Áreas de Educação Física, Esporte e afins \\
\hline Revista Brasileira de Futsal e Futebol & $\begin{array}{l}\text { O Futsal, o Futebol e a Pedagogia do Esporte } \\
\text { no sentido da aprendizagem, da iniciação e do } \\
\text { alto rendimento no âmbito do esporte, da edu- } \\
\text { cação e da sociedade }\end{array}$ \\
\hline Revista Brasileira de Medicina do Esporte & Medicina do Exercício e do Esporte \\
\hline Revista Brasileira de Ortopedia & Ortopedia e campos correlatos \\
\hline $\begin{array}{c}\text { Revista Brasileira de Prescrição e Fisiologia do Exer- } \\
\text { cício }\end{array}$ & $\begin{array}{c}\text { Prescrição do Exercício Físico com parâmetros } \\
\text { na fisiologia do exercício, do esforço humano } \\
\text { no âmbito da saúde, do esporte, da educação, e } \\
\text { do lazer }\end{array}$ \\
\hline Revista de Educação Física/UEM & Área da Educação Física \\
\hline $\begin{array}{l}\text { Revista de Terapia Ocupacional da Universidade de } \\
\text { São Paulo }\end{array}$ & Campo da Terapia Ocupacional e áreas afins \\
\hline Revista Saude.Com & $\begin{array}{l}\text { Área da saúde, abrangendo as subáreas das } \\
\text { Ciências Biológicas, Educação Física, Enfer- } \\
\text { magem, Fisioterapia, Medicina, Nutrição, Psi- } \\
\text { cologia e Odontologia, entre outras }\end{array}$ \\
\hline Salusvita & Não há informações no site \\
\hline
\end{tabular}

Fonte: Elaborado pelos autores, 2016.

No que se refere aos escopos dos periódicos, observam-se algumas com especificidades bem definidas quanto às suas esferas de atuação. Como as das áreas médicas, fisioterapêuticas, de saúde e terapia ocupacional, que não apresentam, conforme lembra Tani (2014), uma identidade inequívoca com a Educação Física. Dentro dos periódicos de grande aderência, encontram-se os de escopo especifico (Fisiologia do Exercício, Cineantroprometria, Pedagogia do Esporte, Gestão), como também os que apresentam uma delimitação mais abrangente. Essa linha editorial mais ampla pode ser observada na $R B C E$, que, embora apresente uma maior afinidade com estudos amparados nas ciências humanas, também vincula frequentemente trabalhos com outras bases epistemológicas ${ }^{5}$. O oposto também é encontrado. Caso da RBEFE, da Revista de Educação Física/UEM, da Motriz e da RBCM, que, mesmo tendo um escopo amplo e publicando frequentemente estudos nas humanidades, vinculam em suas páginas mais estudos amparados num referencial das ciências naturais ${ }^{6}$.

A diversidade de periódicos que publicam estudos relacionados com o basquetebol indica que as pesquisas vêm sendo realizadas com uma variedade de abordagens. Essa heterogeneidade pode ser visualizada no Gráfico 3:

Gráfico 3 - Distribuição de artigos por eixos temáticos - Sistematizado pelos autores

\footnotetext{
${ }^{5}$ O Colégio Brasileiro de Ciências do Esporte (CBCE) é uma entidade científica que se consolidou na área da Educação Física no Brasil por sua afinidade teórica com o discurso das ciências humanas. Seu periódico, a $R B C E$, se tornou um importante meio de divulgação do referencial humanístico na Educação Física brasileira. Mais detalhes sobre este periódico consultar Almeida; Bassani; Vaz (2015).

${ }^{6}$ Sobre a Revista da USP, recomenda-se a o artigo de Moreira (2014). No que se refere ao periódico da UEM, sugere-se a leitura do texto de Vieira et. al (2014).
} 


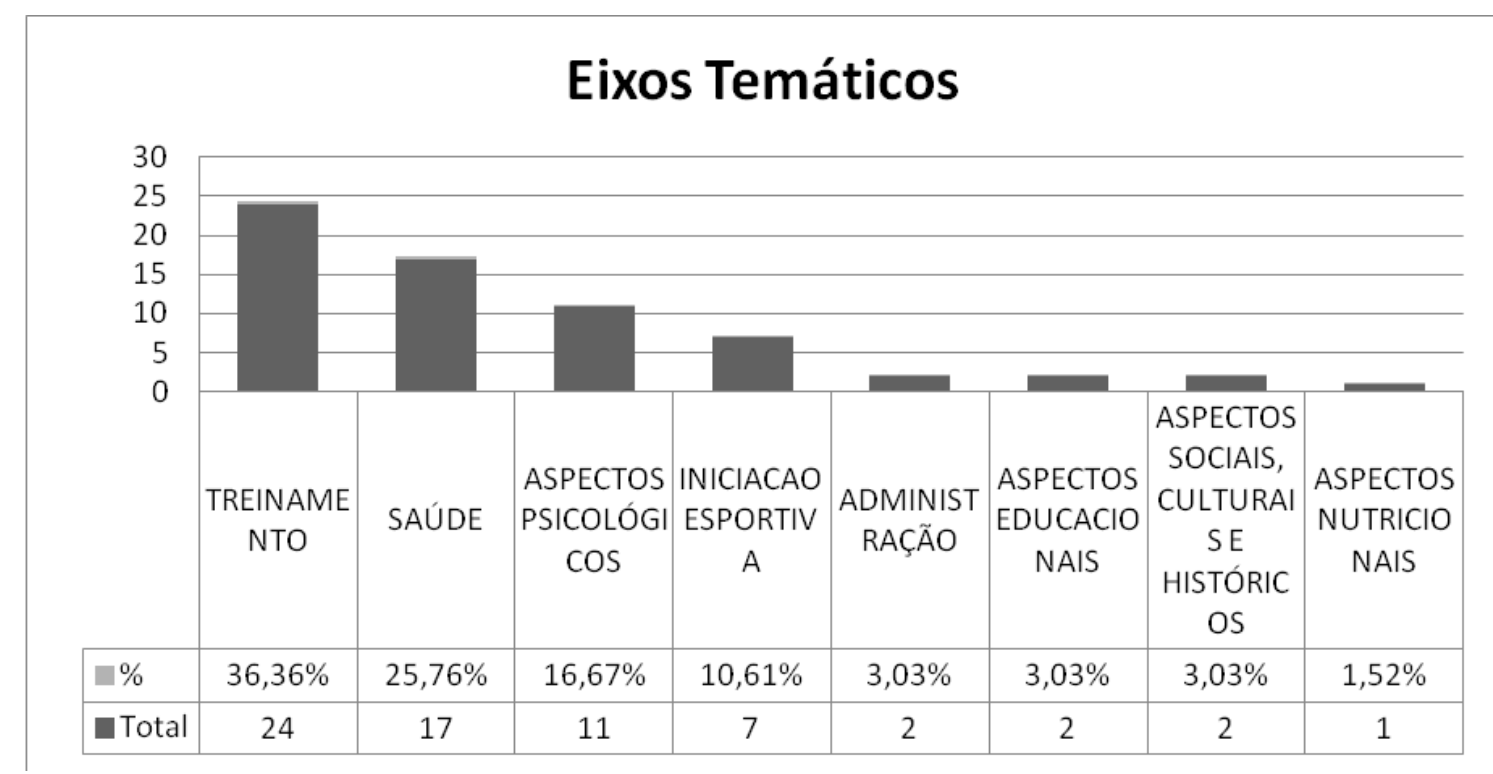

Fonte: Elaborado pelos autores, 2016.

Os artigos enquadrados dentro do eixo temático Treinamento são predominantes. Em seguida, aparecem os enfoques da Saúde, de Aspectos Psicológicos e de Iniciação Esportiva. Com os menores números surgem Aspectos Educacionais, Administração, Aspectos Sociais, Culturais e Históricos e, também, Nutricionais, que juntos publicaram somente sete artigos.

O eixo Treinamento exibe formas diversificadas de abordar a temática. Dentre os 23 artigos catalogados, constam trabalhos como: efeitos de modelos de treinamento; avaliações fisiológicas e/ou biomecânicas de atletas; construção e validação de instrumentos; análises estatísticas etc. Eles foram publicados em uma diversidade de periódicos tais como: Motriz, RBPFE, RBCM, RBCDH, RBCE, RBEFE, RBME, Salusvita e Revista de Educação Físi$\mathrm{ca} / U E M$.

Os manuscritos classificados no eixo Saúde apresentam estudos com uma predominância de temas relacionados às lesões esportivas: classificação das lesões; técnicas de tratamento e relatos de casos de lesões em atletas de basquetebol. Tais artigos se encontram nas páginas da RBO, Revista Brasileira de Clínica Medica; RBPFE, RBCE, RBME, Conscientiae Saúde, Fisioterapia em Movimento, Revista de Terapia Ocupacional da USP, Fisioterapia e Pesquisa e Revista Saúde.com.

Com 11 artigos publicados, os Aspectos Psicológicos contam com estudos sobre: motivação, estresse, comportamentos alimentares etc. Essas publicações se encontram nos seguintes periódicos: RBEFE, RBCE, RBCM, RBME, Motriz e Revista de Educação Físi$c a / U E M$. Já os trabalhos do eixo temático Iniciação Esportiva trazem estudos voltados para a formação de atletas, métodos de ensino e aprendizagem. Seus artigos se materializaram na RBCDH, Motriz, RBFF, RBPFE e RBEFE.

Com um menor número aparecem os Aspectos Educacionais, com um estudo sobre a utilização do livro didático em aulas sobre o basquetebol na Educação Física escolar, publicado na Motriz, e outro voltado à transmissão de valores humanos por meio do basquetebol nas aulas de Educação Física, vinculado na $R B F F$. A baixa produção nessa temática merece uma ressalva especial. Afinal existe, conforme aponta Bracht (2015), uma relação histórica da identidade da Educação Física com a prática pedagógica. As modalidades esportivas, no caso do basquetebol, são tradicionais conteúdos da Educação Física escolar. Contudo, os números mostram uma produção baixíssima nesse item, demonstrando que os próprios pesquisadores ligados à Educação Física escolar não vêm se interessando na pesquisa desse elemento como conteúdo das aulas. Torna-se importante salientar que não se está problematizando a distri- 
buição destes elementos no Qualis, pois a pesquisa não se restringiu a estratos superiores do sistema de avaliação da CAPES. Todas as revistas, independentemente da sua classificação, foram consideradas no presente estudo. Fato que reforça a hipótese na qual os pesquisadores ligados a essa vertente não têm se mostrado interessados em pesquisar sobre o basquete como um conteúdo de ensino.

Por sua vez, o eixo Administração apresenta dois artigos: um sobre a estrutura organizacional e o perfil do gestor de equipes da modalidade e outro sobre a regulamentação do esporte profissional, ambos publicados na Podium: Sport, Leisure and Turism Review. Com também dois estudos vem o eixo Aspectos Sociais, Culturais e Históricos. O primeiro artigo versa sobre o perfil sociodemográfico e os motivos dos espectadores do basquetebol e o segundo, sobre os recursos financeiros e humanos de atletas do basquetebol. Tais estudos estão presentes nas páginas da $R B C E$ e da RBEFE. Por último, vem o eixo Aspectos Nutricionais apresentando um único artigo, que discorre sobre a suplementação e a influência nas capacidades físicas de praticantes, publicado na Conscientiae Saúde.

Apesar de ocorrer uma predominância da temática do Treinamento, a diversidade de eixos nos trabalhos catalogados é considerável. Esse fenômeno ocorre porque, além de os estudiosos da Educação Física transitarem por áreas distintas, também existem pesquisadores de outras áreas se debruçando em investigar algum aspecto relacionado ao esporte, mostrando a diversidade epistemológica existente na área da Educação Física no Brasil (ROSA; LETA 2011; RIGO; RIBEIRO; HALLAL, 2011; LAZZAROTTI FILHO et al. 2012; TANI, 2014).

Segundo Rigo; Ribeiro; Hallal (2011), o fazer ciência em Educação Física tem se consolidado por meio das conexões e intersecções com outras áreas do conhecimento. Tal proposta explica os motivos pelos quais o basquetebol vem sendo analisado por diversas abordagens dentro da área, como também por pesquisadores externos a ela, ou seja, as pesquisas estão sendo realizadas de diversas e diferentes formas.

A próxima análise versa sobre a autoria/coautoria. Foram encontrados 241 autores para os 66 artigos catalogados. Contudo, para realizar alguns comentários específicos sobre esse tema, selecionaram-se somente os seis autores que mais produziram quantitativamente sobre basquetebol:

Tabela 3 - Autores com mais artigos publicados - Sistematizado pelos autores

\begin{tabular}{cc} 
Autores & Número de artigos \\
\hline Alexandre Moreira & 6 \\
\hline Marcelo Saldanha Aoki & 4 \\
\hline Maria Regina Ferreira Brandão & 4 \\
\hline Fábio Yuzo Nakamura & 3 \\
\hline João Paulo Borin & 3 \\
\hline Gerson dos Santos Leite & 3 \\
\hline
\end{tabular}

Fonte: Elaborado pelos autores, 2016.

Alexandre Moreira colaborou em seis estudos, sendo o pesquisador com o maior número de artigos. O docente é vinculado à Escola de Educação Física e Esportes e ao Programa de Pós-Graduação em Educação Física da USP. Seus estudos são voltados para o treinamento esportivo. Seu mestrado e seu doutorado, realizados no Programa de Pós-Graduação em Educação Física da Universidade Estadual de Campinas (UNICAMP), versaram sobre treinamento no basquetebol. O pesquisador também já exerceu o cargo de editor da Revista Brasileira 
de Educação Física e Esportes, um dos periódicos que mais publicaram sobre basquetebol no Brasil. O autor publicou três artigos na $R B C D H$ e mais um em cada uma das seguintes publicações: RBEFE, RBME e Revista de Educação Física/UEM.

O segundo autor com maior número de publicações é Marcelo Saldanha Aoki, que participou na produção de quatro textos. Todos eles vinculados a Alexandre Moreira. Aoki, também docente da USP, só que em outro campus, o da Escola de Artes, Ciências e Humanidades, e atualmente vinculado como docente ao Programa de Pós-Graduação em Ciência da Atividade Física da USP. Sua formação de graduação em Educação Física ${ }^{7}$, mestrado e doutorado em Biologia Celular foi toda realizada na USP, com pesquisas centradas na área de fisiologia do exercício, com ênfase no metabolismo e na nutrição. Contudo, todas as suas publicações sobre basquetebol versaram sobre treinamento. $\mathrm{O}$ autor publicou seus artigos na $R B C D H$ (três artigos) e outro na $R B M E$.

Com também quatro artigos, aparece a psicóloga Maria Regina Ferreira Brandão. Apesar de sua formação inicial não ser em Educação Física, ela realizou mestrado e doutorado na área, defendidos respectivamente na Universidade Federal de Santa Maria e na Universidade Estadual de Campinas. A docente atualmente tem vínculo com a Universidade São Judas Tadeu, onde é professora do Programa de Pós-Graduação em Educação Física, e os aspectos psicológicos do desempenho esportivo são sua principal área de concentração. A pesquisadora também mantém forte vínculo com o esporte de rendimento, tendo sido psicóloga de uma série de importantes instituições e atletas do país. Publicou seus estudos na $R B M E$, $R B C M, R B P F E$ e ConScientia e Saúde. Torna-se interessante salientar que ela publicou conjuntamente com outros dois autores com maior número de publicações: João Paulo Borin e Gerson dos Santos Leite.

Três outros nomes aparecem com a publicação de três pesquisas. O primeiro deles é Fábio Yuzo Nakamura, graduado no curso de bacharelado em Esporte da USP, com mestrado e doutorado em Ciências da Motricidade pela UNESP de Rio Claro. Atua como professor na Universidade Estadual de Londrina, onde também faz parte do corpo docente do Programa de Pós-Graduação em Educação Física Associado UEM/UEL. Suas pesquisas são voltadas para o treinamento esportivo. Os seus estudos sobre o basquetebol foram publicados na $R B C D H$ (dois artigos) e na Revista de Educação Física/UEM.

O segundo nome é João Paulo Borin, professor da Faculdade de Educação Física da UNICAMP, onde também atua no Programa de Pós-Graduação em Educação Física. Nessa instituição também realizou seus estudos de mestrado e doutorado, ambos versando sobre o treinamento do basquetebol. Dedica todas as suas pesquisas ao treinamento esportivo. $\mathrm{O}$ docente teve seus três artigos publicados na $R B M E$, na $R B C M$ e na Salusvita.

Por último, surge o pós-doutorando em medicina da USP Gerson dos Santos Leite, que realiza seus estudos em fisiologia aplicada ao treinamento esportivo. Ele fez mestrado na UNICAMP, sob orientação de João Paulo Borin, e doutorado supervisionado por Maria Regina Ferreira Brandão - sua dissertação de mestrado versou sobre o basquetebol. As suas publicações saíram nos seguintes periódicos: $R B C M, R B P F E$ e $R B M E$.

Como visto acima, no que se refere à produção relativa ao basquetebol, percebe-se que ela segue o mesmo padrão levantado por Lazarotti Filho et al. (2012), que aponta uma tendência da colaboração de vários autores para a realização dos estudos na área de Educação Física. Afinal, apenas Fábio Yuzo Nakamura não publicou artigos com algum dos outros cinco nomes presentes na Tabela 3. Esse fenômeno das redes de colaboração pode ser observado no Gráfico 4, que demonstra que apenas 7 dos 66 manuscritos foram elaborados por apenas

\footnotetext{
${ }^{7}$ Interessante salientar que o pesquisador também tem graduação em Nutrição, feita posteriormente à de Educação Física na Universidade de Guarulhos.
} 
um autor. Número que corresponde a 10,6\% de toda a publicação, ou seja, quase $90 \%$ da produção sobre basquetebol foi feita na relação autoria/coautoria.

Gráfico 4 - Distribuição de artigos por número de coautores - Sistematizado pelos autores

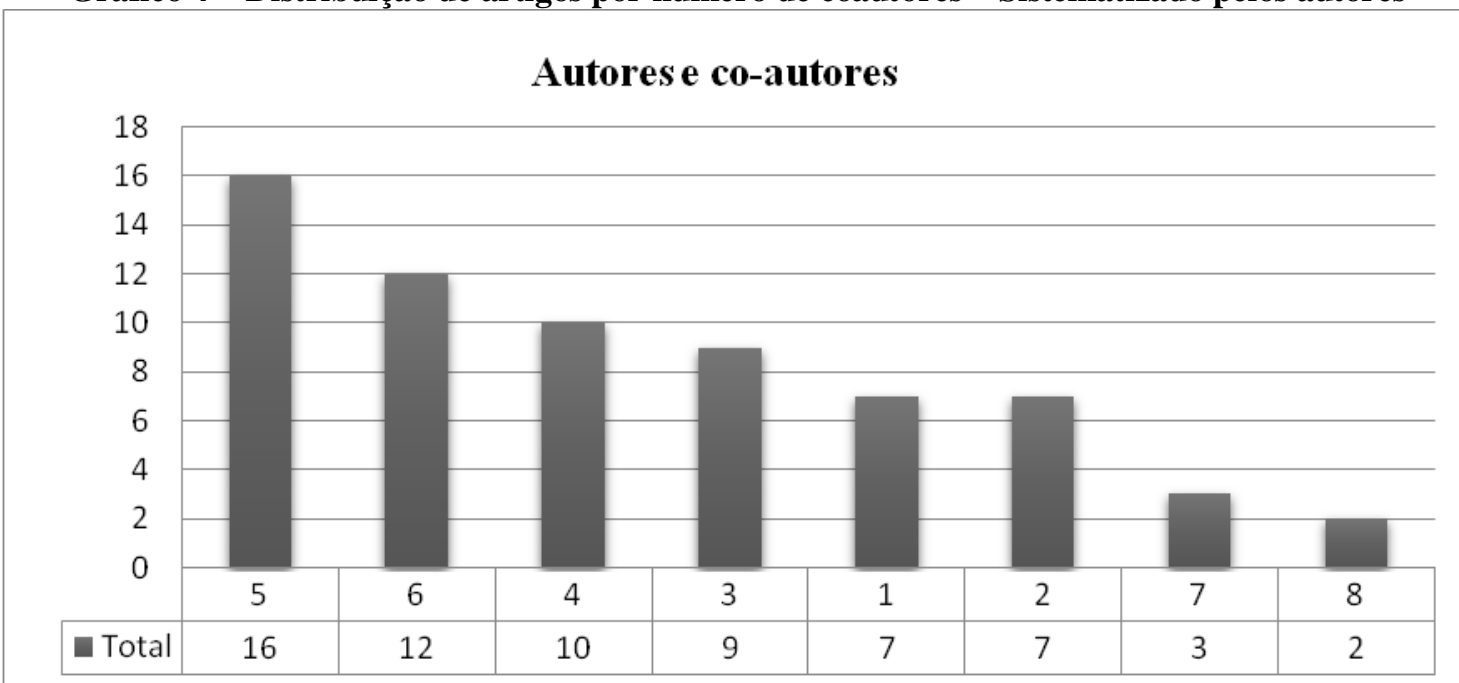

Fonte: Elaborado pelos autores, 2016.

Ao analisar o Gráfico 4, nota-se que a publicação de artigos com colaboradores tem se tornado uma prática comum na área da Educação Física. Como visto, esse modus operandi, de múltipla autoria na área da Educação Física, já levantado anteriormente por Lazarotti Filho et. al. (2012), se mantém na produção relativa ao basquetebol.

Um cenário diferente é observado em relação ao número de instituições colaboradoras na produção científica. Porém, mesmo com um quadro alterado, ainda assim é possível visualizar uma rede de colaboração institucional atuando no fazer ciência.

Gráfico 5 - Distribuição por número de instituições colaboradoras - Sistematizado pelos autores

\section{Instituições por artigo}

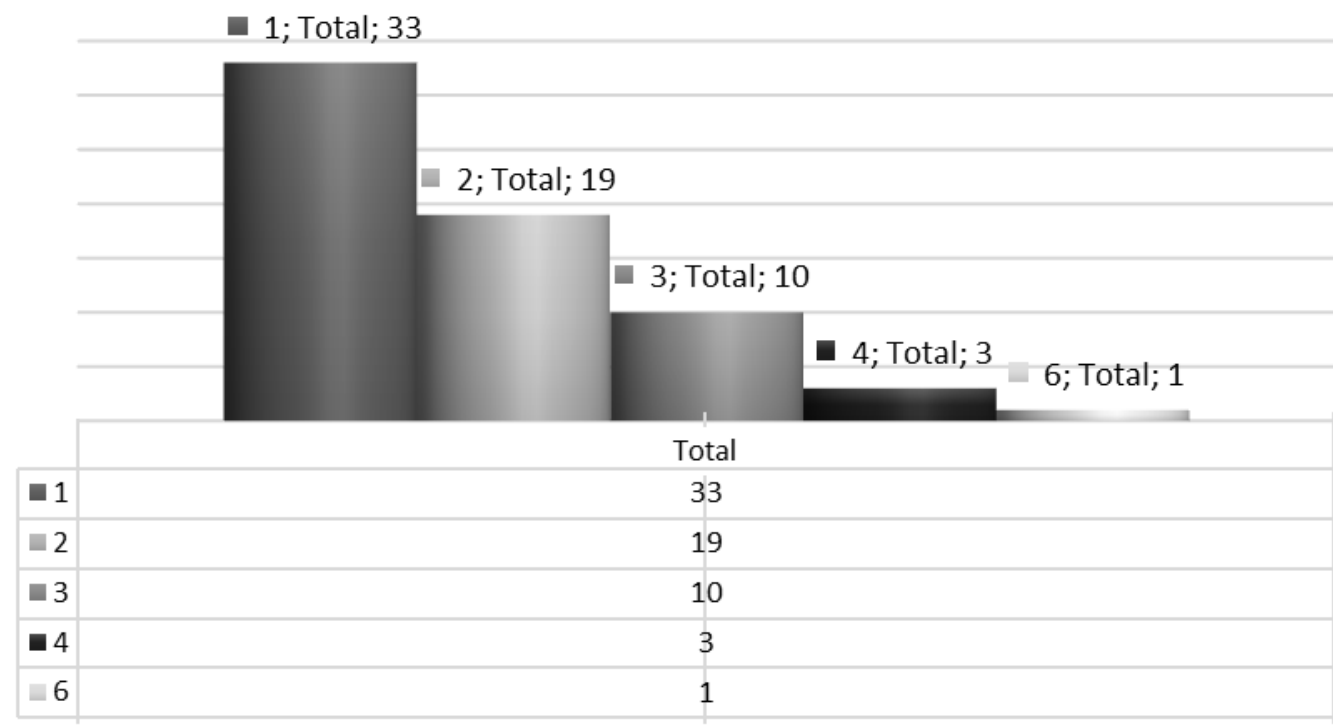

Fonte: Elaborado pelos autores, 2016.

Como pode ser visto no Gráfico 5, são predominantes os trabalhos que foram produzidos por membros de uma única instituição. Os números revelam que 33 textos, ou seja, 50\% 
dos artigos foram realizados por autores do mesmo quadro institucional. Já a outra metade é composta por artigos com mais de uma instituição envolvida.

O Gráfico 6 apresenta uma listagem das instituições que tiveram o maior número de artigos publicados:

Gráfico 6 - Número de artigos publicados pelas instituições - Sistematizado pelos autores

\section{Instituições com o maior publicação}

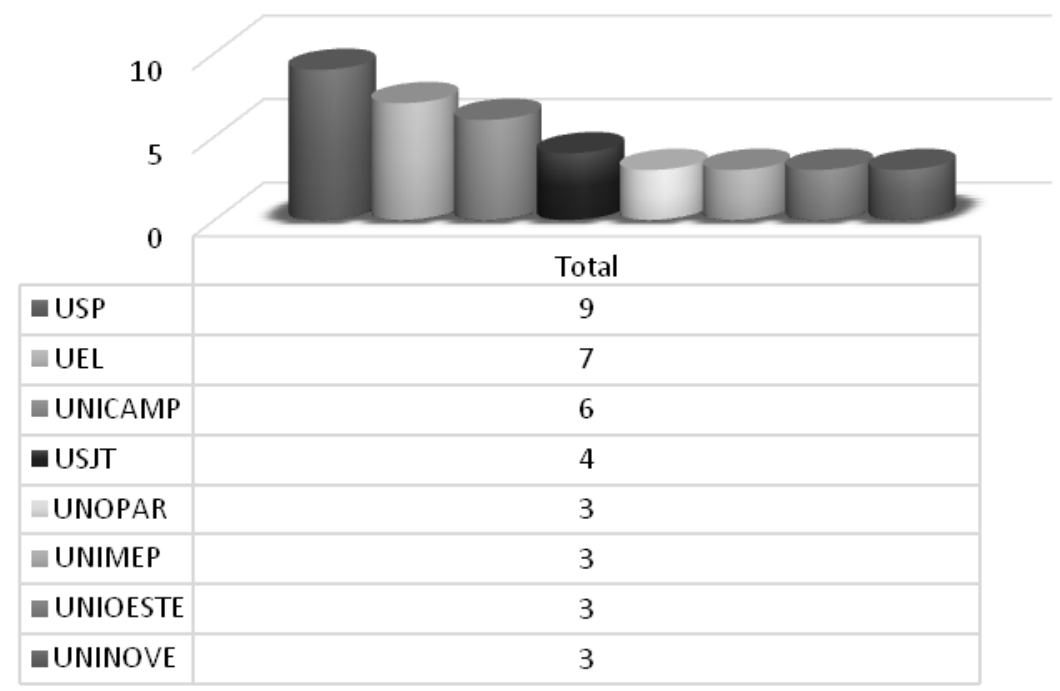

Fonte: Elaborado pelos autores, 2016.

Como pode ser visto no gráfico acima, a USP aparece com o maior número de artigos na produção sobre o basquetebol, confirmando o papel protagonista que a instituição exerce na área de Educação Física sinalizado por Rosa; Leta (2010; 2011). A instituição contou com nove manuscritos publicados pelos seus pesquisadores. Em seguida, aparecem a UEL, com sete artigos; a UNICAMP, com seis, e a USJT, com quatro. Com três publicações cada uma, aparecem a UNOPAR, a UNIMEP, a UNIOESTE e a UNINOVE. Torna-se interessante salientar que todas as instituições citadas no Gráfico 6 estão localizadas nos estados do Paraná e de São Paulo. Rosa; Leta (2010) indicam que esse papel protagonista da USP na produção na área de Educação Física é de certa forma esperado, visto que a instituição também lidera esse quadro em diversas outras áreas do conhecimento. Outro ponto a ser mencionado é que seu Programa de Pós-Graduação em Educação Física é o único a ter o conceito 7, o máximo que pode ser obtido no atual sistema de avaliação da CAPES.

No se refere às unidades federativas nas quais as instituições e seus pesquisadores estão alocados, observa-se que novamente São Paulo é o estado com o maior número de instituições produzindo sobre a modalidade. 
Gráfico 7 - Estados com maior número de instituições - Sistematizado pelos autores

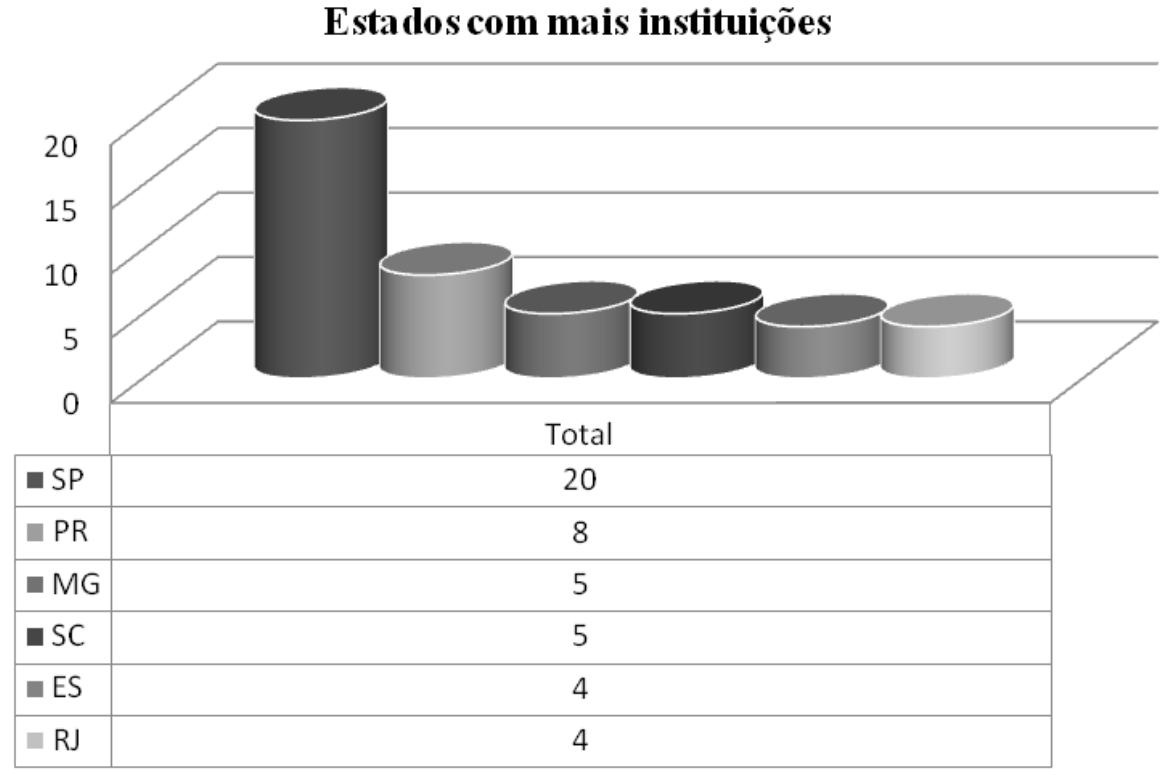

Fonte: Elaborado pelos autores, 2016.

O gráfico apresenta um cenário no qual existe uma presença majoritária de instituições localizadas na região Sudeste e Sul do país. São Paulo aparece com 20 instituições, seguido pelo Paraná (8), Minas Gerais (5), Santa Catarina (5), Espírito Santo (4) e Rio de Janeiro (4). Esses números vão ao encontro das análises empreendidas por Manoel; Carvalho (2011), as quais indicam que essas regiões são onde se concentram o maior número de programas de pós-graduação em Educação Física. Ao relacionar os dados do presente mapeamento com os apontamentos dos autores, observa-se um indicativo de que os programas de pós-graduação são um elemento significativo para o fomento da produção do conhecimento e a própria lógica de publicação de artigos em periódicos científicos. Afinal, todos os seis autores que figuram na listagem de maior produção quantitativa estão diretamente ligados a um programa de pós-graduação em Educação Física ou similares, localizados principalmente nos estados de São Paulo e Paraná.

\section{Considerações finais}

O presente artigo buscou mapear a produção de conhecimento sobre o basquetebol. Procurou-se identificar em que medida a modalidade foi estudada, bem como as diversas formas epistemológicas como foi tratada. Vale salientar que se reconhecem as limitações que o estudo apresenta, uma vez que somente foram utilizados artigos redigidos em língua portuguesa e publicados em periódicos nacionais, ainda mais num contexto em que a internacionalização é algo presente e contundente na área da Educação Física, como apontaram os estudos de Manoel; Carvalho (2011) e Tani (2014).

Como resultado, o estudo catalogou um número de 66 artigos publicados em 18 diferentes periódicos. O maior número foi registrado na $R B E F E$ e na $R B M E$, seguidas pela $R B C E$, RBCDH, Motriz e Revista de Educação Física/UEM. O treinamento apareceu como eixo temático com maior número de estudos publicados. Uma ressalva merece ser feita neste momento. Apesar de os artigos sobre treinamento terem sido os preponderantes, não se pode considerar essa produção abrangente, visto que o número apresentado é muito pequeno para uma modalidade tradicional no país como o basquetebol. Afinal, como aponta Nakamura 
(2015), a pesquisa em treinamento esportivo no Brasil, independentemente de ter pesquisadores qualificados e com boa inserção internacional, ainda se encontra numa fase incipiente.

Ainda que exista uma predominância do eixo Treinamento, foi possível visualizar uma diversidade epistemológica nos trabalhos sobre o basquetebol, visto que essa modalidade foi tratada sob diversos enfoques epistemológicos. O que é salutar para uma área que pretende se consolidar cientificamente. Nesse sentido, assim como os trabalhos sobre treinamento, os estudos amparados em outras maneiras de se abordar o esporte também devem crescer em quantidade e qualidade. Cabe destacar também a baixa produção relativa ao basquetebol como um conteúdo das aulas de Educação Física na escola. Tal condição indica que os pesquisadores ligados a essa vertente não parecem estar preocupados em tematizar essa modalidade como conteúdo das aulas de Educação Física.

No que tange ao modelo de produção dos artigos sobre o basquetebol, constatou-se que segue uma perspectiva de rede de colaboração, assim como levantaram Lazzarotti Filho et al. (2012). Esse quadro é observado nos números relativos à quantidade de autores e/ou instituições que colaboram entre si.

Já no que se refere aos centros de produção desses artigos, a USP aparece como a instituição com o maior número de manuscritos publicados, seguindo a tendência apontada anteriormente por Rosa; Leta $(2010 ; 2011)$. Outras universidades paulistas se destacam, como a UNICAMP, a USJT, a UNIMEP e a UNINOVE, bem como algumas instituições do estado do Paraná, como o caso da UEL, da UNOPAR e da UNIOESTE. Como visto, as regiões Sul e Sudeste são as que apresentam o maior número de instituições que estão produzindo sobre a modalidade, o que pode ser explicado pelo fato, conforme apontam Manoel e Carvalho (2011), de os programas de pós-graduação em Educação Física estarem basicamente concentrados nessas localidades, principalmente no estado de São Paulo.

Portanto, pode-se concluir que o presente estudo apresenta uma contribuição para a comunidade acadêmica, apontando o modus operandi relativo à produção do conhecimento acerca do basquetebol, incentivando, assim como preconiza Nakamura (2015), uma maior produção sobre os esportes no Brasil. E também indicando a importância que a modalidade tem em diversos setores, colaborando para avanços do conhecimento sob diversos enfoques epistemológicos.

\title{
MAPPING THE KNOWLEDGE CREATION ABOUT BASKETBALL IN BRAZILI- AN SCIENTIFIC JOURNALS
}

\begin{abstract}
This study aims to map the production of knowledge about the Basketball modality published in Brazilian journals between 2010 and 2015. The survey pointed out that production on basketball totaled 66 articles, distributed in 18 scientific journals, being the largest number on sports training. Regarding classification by strata of Qualis, is predominant those ranked in stratum B1. A trend in production was also observed in the form of a collaborative network among authors. To closure, the academic points out that the production on basketball, although small quantitatively and with predominance in the training theme, presents itself epistemologically diversified.
\end{abstract}

Keywords: Basketball. Knowledge. Scientific Journals. 


\title{
EL MAPEO DE LA PRODUCCIÓN DE CONOCIMIENTOS SOBRE LA MODALI- DAD DEL BALONCESTO EN LAS REVISTAS BRASILEÑAS
}

\begin{abstract}
Resumen
Este estudio tiene como objetivo hacer el mapeo de la producción de conocimiento sobre la modalidad de baloncesto publicada en revistas brasileñas, en el período comprendido entre los años 2010 y 2015. El análisis mostró que la producción sobre el baloncesto sumó 66 artículos, distribuidos en 18 revistas científicas, siendo el mayor número sobre entrenamiento deportivo. En cuanto a la clasificación por estratos de Qualis, predominan los que están clasificados en el estrato B1. También se observa una tendencia de la producción en la forma de una red de colaboración de autores. En conclusión, el estudio muestra que la producción sobre el baloncesto, aunque pequeña cuantitativamente y predominantemente en la temática de entrenamiento, se presenta diversificada epistemológicamente.
\end{abstract}

Palabras clave: Baloncesto. Producción de Conocimiento. Periódicos.

\section{Referências}

ALMEIDA, F. Q.; BASSANI, J. J.; VAZ, A. F. Vicissitudes de uma história da RBCE: 35 anos de editoração científica (1979-2013). Motrivivência, v. 27, n. 46, p. 135-153, 2015.

BRACHT, V. Desafios e dilemas da pós-gradução em educação física: conhecimento e especificidade. In: Rechia, S. et al. (Org.). Dilemas e desafios da pós-graduação em Educação Física. Ijuí: Ed. UNIJUİ, 2015, p. 109-123.

LAZZAROTTI FILHO, A. et al. Modus operandi da produção científica da EF: uma análise das revistas e suas veiculações. Revista da Educação Física/UEM, v. 23, p. 1-14, 2012.

MANOEL, E. J.; CARVALHO, Y. M. Pós-graduação na educação física brasileira: a atração (fatal) para a biodinâmica. Educação e Pesquisa, v. 37, n. 2, p. 389-406, 2011.

MOREIRA, A. A busca continuada pela qualidade, visibilidade, interatividade e popularização do conhecimento: o caso da Revista Brasileira de Educação Física e Esporte. Revista Brasileira de Ciências do Esporte, v. 36, n. 4, p. 759-764, 2014.

NAKAMURA, F. Y. A produção do conhecimento acerca do treinamento esportivo no Brasil: análise a partir dos eventos do CBCE e do GPMCE. In: RECHIA, S. et. al. (Org.). Dilemas e desafios da pós-graduação em Educação Física. Ijuí: Ed. UNIJUİ, 2015. p. 393-407.

RIGO, L. C.; RIBEIRO, G. M.; HALLAL, P. C. Unidade na diversidade: desafios para a Educação Física no século XXI. Revista Brasileira de Atividade Física \& Saúde, v. 16, n. 4, p. 339-345, 2011.

ROSA, S. P.; LETA, J. Tendências atuais da pesquisa brasileira em Educação Física. Parte 1: uma análise a partir de periódicos nacionais. Revista Brasileira de Educação Física e Esporte, v. 24, p. 121-134, 2010.

Tendências atuais da pesquisa brasileira em Educação Física. Parte 2: a heterogeneidade epistemológica nos programas de pós-graduação. Revista Brasileira de Educação Física e Esporte, v. 25, n. 1, p. 7-18, 2011. 
SOUZA, D. L; MORAES E SILVA, M; MOREIRA, T. S. O perfil da produção científica online em português relacionada às modalidades olímpicas e paralímpicas. Movimento, Porto Alegre, 2016. (no prelo)

TANI, G. Editoração de periódicos em Educação Física/Ciências do Esporte: dificuldades e desafios. Revista Brasileira de Ciências do Esporte, v. 36, n. 4, p. 715-722, 2014.

VIEIRA, J. L. L. et al. Dossiê Revista da Educação Física/UEM: contextualização histórica, desenvolvimento e perspectivas. Revista Brasileira de Ciências do Esporte, Florianópolis, v. 36, n. 4, 2014.

Recebido em: 15/06/2016

Revisado em: 06/10/2016

Aprovado em: 08/12/2016

Endereço para correspondência:

jeferson.rojo@hotmail.com

Jeferson Roberto Rojo

Universidade Federal do Paraná

Rua XV de Novembro, 1299

Centro, Curitiba - PR, 80060-000 